\section{Vegetative Characterization of Wild Grapevines (Vitis spp.) Native to Puebla, Mexico}

\author{
Omar Franco-Mora', Edgar Jesús Morales-Rosales, and \\ Andrés González-Huerta \\ Centro de Investigaciones y Estudios Avanzados en Fitomejoramiento, \\ Facultad de Ciencias Agrícolas, Universidad Autónoma del Estado de \\ México, Campus El Cerrillo, Toluca, México, C.P. 50200
}

\section{Juan Guillermo Cruz-Castillo}

Centro Regional Universitario Oriente, Universidad Autónoma Chapingo, Km 6 Carr, Huatusco-Xalapa, Veracruz, México

Additional index words. descriptors, genetic conservation, germplasm resources, native uses, mapping

\begin{abstract}
Thirty-four accessions of wild grapevines, native to three regions of the state of Puebla, Mexico, that is Teziutlán, Tehuacán, and Atlixco, were vegetatively characterized with 32 suggested IPGRI, UPOV, and OIV descriptors related to young shoot (YS), mature shoot (MS), young leaf (YL), mature leaf (ML), and woody shoot (WS). Excepting profile and absence of sinus teeth in ML, the remaining parameters showed variation among the accessions. After the performance of a correlation analysis among the 32 characters, only those closely correlated were used; that is, for MS: color of dorsal side of node, density of prostrate trichomes of internode; for YL: density of prostrate trichomes between veins and density of erect trichomes on main veins; and for ML: general shape of petiole sinus and the density of erect trichomes on veins in mature leaves. With those six characters, six principal components explained the total variability observed. The most closely related descriptors for principal Component 1 were the ML general shape of petiole sinus $(-0.735)$ and the YL density of erect trichomes on main veins $(0.659)$, whereas for principal Component 2, the MS color of the dorsal side of the node $(0.677)$ and the density of erect trichomes in ML (0.596) were the most highly related. A cluster analysis identified four groups with a euclidean distance of 18; except for plant 183, the other six included in Group 1 were native to the regions Atlixco and Tehuacán; Group 2 was formed by plants native to the three regions, whereas Group 3 was formed by plants native to Teziutlán and Atlixco; Group 4 was formed only by Plant 36, native to Atlixco. These results show that variation among accessions occurs within and among the three states of the Puebla region.
\end{abstract}

In several regions of Mexico, the presence of wild grapevines has been reported (Franco-Mora et al., 2007, 2008; Martínez et al., 2007). However, as observed in other countries such as France, Spain, and Japan, the number of wild genotypes seems to decrease attributable, at least in part, to human disruption of their natural habitat and the use of few commercial cultivars and rootstocks (Boursiquot, 2000; Martí et al., 2006; Motosugi et al., 2007; Ocete et al., 2008; Santiago et al., 2008). Few countries have started to protect wild grapevine populations; however, Spain has an interesting program for the protection of $V$. vinifera $\mathrm{L}$. spp. silvestris and other traditional cultivars from direct and indirect human activities (Navarro et al., 2008; Ocete et al., 2008; Santiago et al., 2008). In an attempt to contribute to the conservation of the diversity

Received for publication 3 Mar. 2008. Accepted for publication 2 Aug. 2008.

${ }^{1}$ To whom reprints request should be addressed; e-mail ofm@uaemex.mx in the genus Vitis in Mexico, a national program was initiated in 2005 aimed at the collection and description of wild grapevine ecotypes. In the state of Puebla in central
Table 1. Plants native to Atlixco, state of Puebla, region.
Mexico, between 2005 and 2007, more than 200 grapevines were located and four main regions were described and named Totonacapan, Atlixco, Teziutlán, and Tehuacán (Franco-Mora et al., 2008). Plants in those three former regions were found growing on mountains, hills, valleys, and near small riverbanks, sharing the environment with Citrus, Vanilla, Zea mays L., Sacharum officinarum L., Annona cherimola Mill., and several other species. Successfully propagated plants are conserved in three germplasm gardens located in Toluca, México; Huatusco, Veracruz; and Teziutlán, Puebla (Cruz, 2007; Franco-Mora et al., 2007, 2008). Native people report using these plants for the consumption of fresh berries, preparation of jelly, drinking shoot water, and, interestingly, the use of leaves to prepare tea for treating cardiovascular diseases (FrancoMora et al., 2008). Similar uses have been reported in Brazil, China, Japan, and Spain (Camargo, 2000; Huang and Lin, 1999; Li et al., 2006; Lu, 2005; Martí et al., 2006; Navarro et al., 2008; Ocete et al., 1997, 2008; Oshima and Kamijou, 1995; Santiago et al., 2008).

It has been shown that characterization of the morphological, biochemical, or molecular traits of Vitis genetic resources might help in the development of horticulture, pharmaceutical, and other industries $(\mathrm{Lu}$, 2005). In Spain, native and commercial grapevines have been characterized by morphological and biochemical description as well as molecular studies, and these methods have been shown to be complementary (Asencio et al., 2002; Martí et al., 2006; Santiago et al., 2008). Also in Spain, a combination of morphological characterization and testing of susceptibility to pests and diseases was used to describe populations of $V$. vinifera spp. silvestris (ArroyoGarcía et al., 2006). After the formation of a Vitis germplasm collection at the Universidad Autónoma del Estado de México (UAEMex), Toluca, state of Mexico, one of the main goals is the complete description, i.e., morphological and molecular, of its

\begin{tabular}{rlcl}
\hline No. & \multicolumn{1}{c}{ Municipality } & Altitude $(\mathrm{m})$ & Original environment \\
\hline 3 & Nealtican & 2,210 & Backyard \\
10 & San Lorenzo Chiautzingo & 2,540 & Mountain with agriculture use \\
13 & Atlixco & 2,056 & Deep hollow near riverbank \\
14 & Atlixco & 2,056 & Deep hollow near riverbank \\
36 & Atlixco & 2,065 & Deep hollow near riverbank \\
187 & Atlixco & 2,059 & Hill \\
17 & Izúcar de Matamoros & 1,284 & Backyard \\
31 & San Juan Tianguismanalco & 2,149 & Hill \\
33 & San Juan Tianguismanalco & 2,160 & Hill \\
35 & San Juan Tianguismalco & 2,150 & Hill \\
121 & Tepeojuma & 1,483 & Behind cane plantation and \\
& & & agricultural water duct \\
123 & Tepeojuma & 1,488 & Around cane plantation, over \\
& & & cherimoya fruit tree \\
126 & Tepeojuma & 1,480 & Around cane plantation, over \\
& & & guava fruit tree \\
128 & Tepeojuma & 1,476 & Around cane plantation, \\
& & & near riverbank \\
130 & Tepeojuma & 1,477 & Riverbank \\
\hline
\end{tabular}


accessions. Thus, the present research is an initial study aimed at the vegetative characterization of the state of Puebla native grapevine resources and was conducted to assess vegetative diversity and vegetative relationship among 34 Vitis accessions growing in a germplasm garden in Toluca, Mexico. Correct identification of these genotypes is necessary for their inscription into national and international organisms related to the protection of the biodiversity of plants.

\section{Material and Methods}

Thirty-four accessions, belonging to the "Vitis Collection of the UAEMex", were selected for a three-replication vegetative characterization with one plant per replication. Those accessions were native to three states of the Puebla region, that is Atlixco, Teziutlán, and Tehuacán (FrancoMora et al., 2008); in this characterization, 15,12 , and seven accessions of each region, respectively, were described (Tables 1-3). Plants were 2 years old with a height of $\approx 1.5 \mathrm{~m}$ and trained with a stake. They were growing on a peatmoss:perlite:coconut fiber (1:2:1) medium under greenhouse conditions.

Description of the accessions was done according to the "Descriptors for grapevine (Vitis spp.)" (IPGRI, UPOV, and OIV, 1997) and included 32 vegetative characters related to young (YS), mature (MS), and woody shoot (WS) and young (YL) and mature leaf (ML) (Tables 4-8). After vegetative determinations, data were first correlated with the method of Pearson; then, only the highly correlated descriptors were selected and used to perform a cluster analysis by the unweighted pair group method with arithmetic mean. Finally, a principal component analysis was performed, and the original sites of collection with the clustered group (at a euclidean distance of 18) were located on a map with the DIVA-GIS software.

\section{Results and Discussion}

For all the 32 descriptors used in this work, with the exception of ML profile and the general absence of teeth at the petiole sinus, differences among the 34 accessions were observed (data not shown). Asencio et al. (2002) found 14 of 44 characters with similar values for the young shoot, young leaf, shoot, tendrils, and mature leaves in 11 cultivars of $V$. vinifera growing in Extremadura, Spain. Results of the present work suggest that the variability within the several vegetative characters in Puebla wild grapevines is higher in relation to Extremadura commercial cultivars. Vitis living in its native location may be only environmentally selected and in this way shows higher variation than human-selected ones.

Some interesting results in this characterization included the absence, in all the 34

Table 2. Plants native to Teziutlán, state of Puebla, region.

\begin{tabular}{rlcl}
\hline No. & \multicolumn{1}{c}{ Municipality } & Altitude $(\mathrm{m})$ & \multicolumn{1}{c}{ Original environment } \\
\hline 18 & Teziutlán (Aire Libre) & 1,525 & Deep hollow near riverbank \\
21 & Teziutlán (Aire Libre) & 1,520 & Deep hollow near riverbank \\
22 & Teziutlán (Ixtlahuaca) & 1,550 & Hill, house backyard \\
40 & Teziutlán (La minera) & 2,055 & Hill, backyard \\
78 & Teziutlán (Huehuemico) & 1,729 & Hill \\
141 & Teziutlán (S.J. Acateno) & 1,703 & Hill \\
99 & Tlatlauquitepec & 2,164 & Hill, near road \\
106 & Zacapoaxtla & 1,446 & Hill \\
108 & Zacapoaxtla & 1,402 & Hill \\
166 & Ayotoxco & 249 & Corn plantation within hill \\
169 & Ayotoxco & 166 & Riverbank and pasture ground \\
183 & Hueytamalco & 417 & Near waterfall \\
\hline
\end{tabular}

Table 3. Plants native to Tehuacán, state of Puebla, region.

\begin{tabular}{llcc}
\hline No. & Municipality & Altitude $(\mathrm{m})$ & Original environment \\
\hline 23 & Chapulco & 2,011 & Backyard \\
26 & Chapulco & 2,011 & Backyard \\
27 & Chapulco & 2,011 & Backyard \\
29 & Chapulco & 2,012 & Backyard \\
64 & Juan N. Méndez & 1,940 & Backyard \\
65 & Juan N. Méndez & 1,943 & Backyard \\
67 & Tochtepec & 2,014 & Backyard \\
\hline
\end{tabular}

Table 4. Young shoot characters used to describe 34 accessions of Vitis spp. native to the state of Puebla, Mexico.

Character (IPGRI number) $\quad$ Forms

Form of tip (6.1.1) Closed; slightly open; half open; wide open; fully open

Coloration of tip (6.1.2)

Density of prostrate trichomes

on tip (6.1.3)

Density of erect trichomes on tip (6.1.4)

Absent; very weak; weak; medium; strong; very strong

Absent; very sparse; sparse; medium; dense; very dense

Absent; very sparse; sparse; medium; dense; very dense

Table 5. Shoot characters used to describe 34 accessions of Vitis spp. native to the state of Puebla, Mexico.

Character (IPGRI number)

Habit (attitude) (6.1.5)

Color of dorsal side of internode (6.1.6)

Color of ventral side of internode (6.1.7)

Color of dorsal side of node (6.1.8)

Color of ventral side of node (6.1.9)

Density of erect trichomes

of node (6.1.10)

Erect trichomes of internode (6.1.11)

Density of prostrate trichomes

of node (6.1.12)

Density of prostrate trichomes of internode (6.1.13)
Erect; semierect; horizontal; seme-dropping; dropping

Completely green; green and red striped; completely red

Completely green; green and red striped; completely red

Completely green; green and red striped; completely red

Completely green; green and red striped; completely red

Absent; very sparse; sparse; medium; dense; very dense

Absent; presence

Absent; very sparse; medium; very dense

Absent; very sparse; medium; very dense

Table 6. Young leaf characters used to describe 34 accessions of Vitis spp. native to the state of Puebla, Mexico.

\begin{tabular}{ll}
\hline Character & Forms \\
\hline Color of upper surface (6.1.16) & $\begin{array}{c}\text { Green; green with bronze spots; yellow; yellow with bronze spots; } \\
\text { copper yellow } \\
\text { Absent; very sparse; sparse; medium; dense; very dense }\end{array}$ \\
$\begin{array}{l}\text { Density of prostrate trichomes } \\
\text { between veins (6.1.17) }\end{array}$ & Absent; very sparse; sparse; medium; dense; very dense \\
$\begin{array}{c}\text { Density of erect trichomes } \\
\text { between veins (6.1.18) }\end{array}$ & Absent; very sparse; sparse; medium; dense; very dense \\
$\begin{array}{c}\text { Density of prostrate trichomes } \\
\text { on main veins (6.1.19) }\end{array}$ & Absent; very sparse; sparse; medium; dense; very dense \\
$\begin{array}{c}\text { Density of erect trichomes on } \\
\text { main veins (6.1.20) }\end{array}$ & \\
\hline
\end{tabular}

accessions, of the YS fully open tip form, suggesting the absence of $V$. vinifera and $V$. berlandieri (IPGRI, UPOV, and OIV, 1997). The nonpresence of $V$. vinifera is supported by the fact that none of these accessions were originally found near vineyards, although accessions from Chapulco are semicultivated. On the other hand, anthocyanin 
Table 7. Mature leaf characters used to describe 34 accessions of Vitis spp. native to the state of Puebla, Mexico.

Character
Shape of blade (6.1.22)
Number of lobes (6.1.23)
Profile (6.1.25)

Profile (6.1.25)

Shape of teeth (6.1.27)

General shape of petiole sinus (6.1.30)

Tooth at petiole sinus (6.1.31)

Petiole sinus limited by veins (6.1.32)

Density of prostrate trichomes between veins (6.1.35)

Density of erect trichomes between veins (6.1.36)

Density of prostrate trichomes on main veins (6.1.37)

Density of erect trichomes on main veins (6.1.38)

Density of prostrate trichomes on main veins (6.1.39)

Table 8 . Woody shoot characters used to describe 34 accessions of Vitis spp. native to the state of Puebla, Mexico.

\begin{tabular}{ll}
\hline Character & \multicolumn{1}{c}{ Forms } \\
\hline Surface (6.1.41) & Smooth; edged; striate; ribbed \\
Main color & Yellow, yellowish \\
$(6.1 .42)$ & brown; dark brown; \\
& reddish brown; violet \\
\hline
\end{tabular}
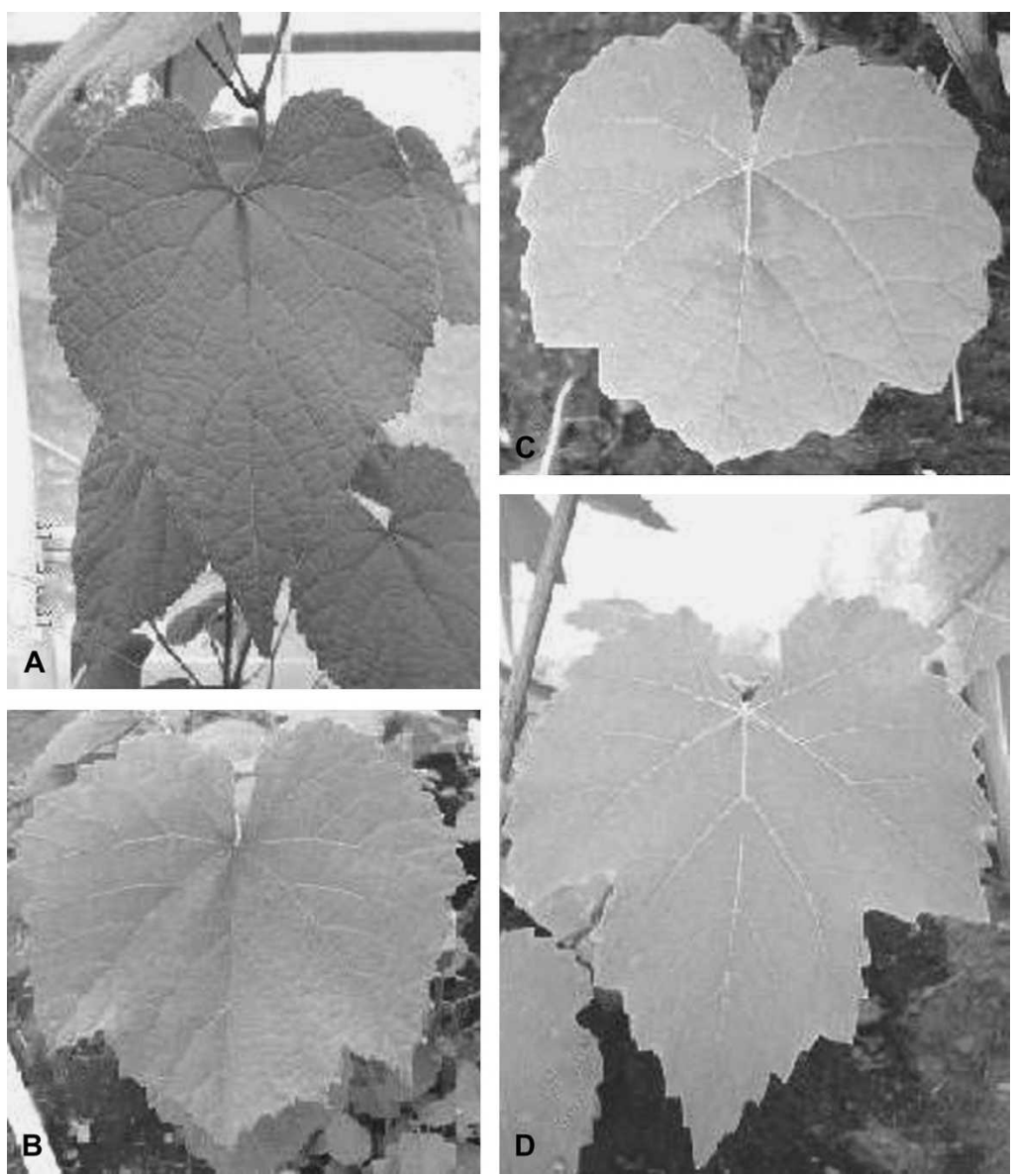

Fig. 1. Mature leaf shapes observed in a Puebla state native grapevine. (A) cordate; (B) wedge-shaped; (C) circular; (D) pentagonal. leaf was cordate, wedge-shaped, pentagonal, and circular (Fig. 1); in this study, nomophyllum was determined as the leaf shape value, although leaf morphological variation within a single plant was observed in several accessions as described by Martí et al. (2006). The number of lobes per leaf ranged from zero (entire leaf) to three or five; entire leaves were observed in five accessions: 14, $22,106,126$, and 166 . With respect to the general shape of the petiole sinus, three of the seven shapes indicated in the descriptor were found: slightly open, half open, and wide open. Mature leaves with the sinus very wide open, closed, or overlapping were not observed.

Cluster analysis identified four groups at a euclidean distance of 18 (Fig. 2); Teziutlán and Atlixco regions showed higher variation, because their different accessions observed characteristics of three and four of the four formed groups, respectively (Fig. 3). Conservation of Vitis in Puebla, Mexico, might be supported not only by the high number of collecting sites (Franco-Mora et al., 2008), but also by the high vegetative variability demonstrated in this ampelographic study (Fig. 2). In Spain, zones serving as refuge areas for Vitis and the occurrence of genotypes with high potential for wine marketing have been reported (Santiago et al., 2008). With the exception of Group 4, formed by only one accession, native to Atlixco, the other three groups contain accessions of at least two regions. Thus, the original collection site is not a conclusive factor to group the Vitis accessions insofar as they present dissimilarities and similarities within the accessions of the same collection site.

Moreover, within the groups, variation was also observed, i.e., at a euclidean distance of 8; in Group 1 the accession 17, native to Izúcar de Matamoros, shows a high difference from the other five accessions; in Group 2, accession 99 was significantly different from the other 12 accessions. In Group 3 , four subgroups were formed at a euclidean distance of 8 , showing also that accession 21 (Teziutlán) is different with respect to the accessions of the other three subgroups. On the other hand, Plants 27 (ChapulcoTehuacán) and 65 (J.N. Méndez-Tehuacán); 3 (Nealtican-Atlixco) and 23 (ChapulcoTehuacán); and 18 (Teziutlán-Teziutlán) and 31 (San Juan Tianguismanalco-Atlixco) were the closely related ecotypes, whereas accessions 36 (Atlixco-Atlixco) and 27 (Chapulco-Tehuacán) were highly unrelated accessions (Fig. 2).

The principal component analysis indicated that the first six principal components identified $100 \%$ of the observed variance (Table 9). For principal Component 1, the highest influence was from the ML general shape of petiole sinus $(-0.735)$ and the YL density of trichomes on main veins $(0.659)$. The MS color of the dorsal side of the node $(0.677)$ and the YL density of erect trichomes on main veins $(0.600)$ were the main influence for principal Component 2 . 


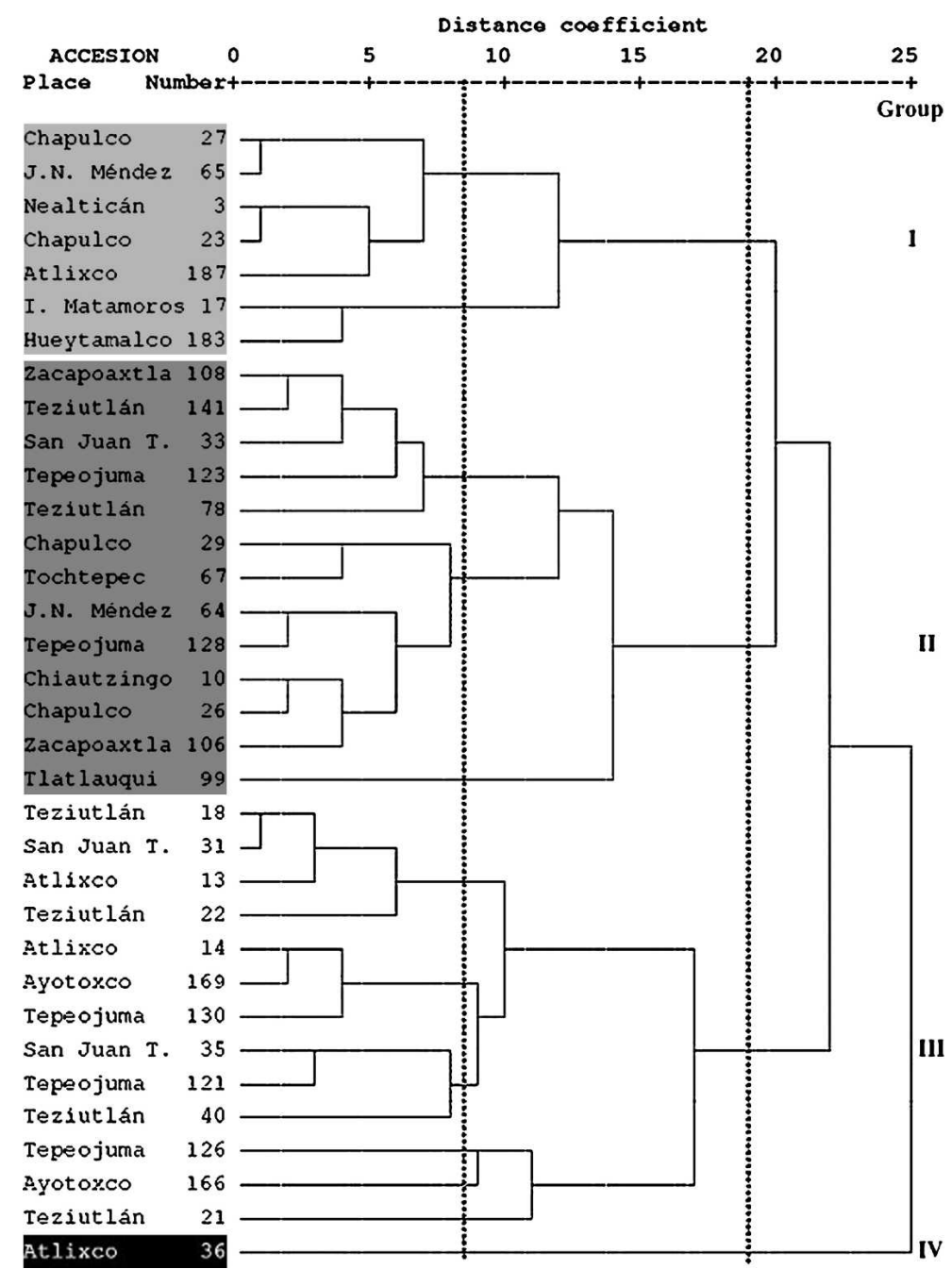

Fig. 2. Dendogram grouping 34 accessions of grapevines native to the state of Puebla, Mexico, according to vegetative description.

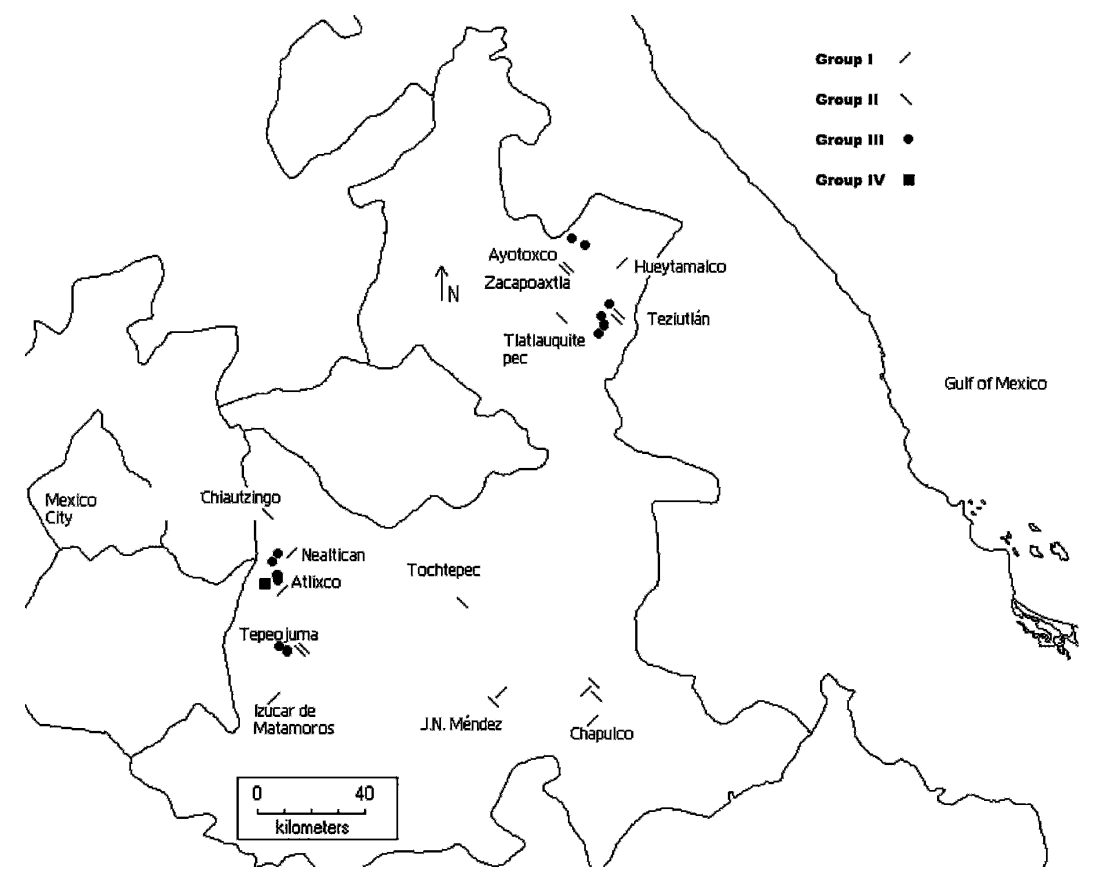

Fig. 3. Location of wild grapevines in the state of Puebla, Mexico, according to the four vegetative described groups formed by a cluster analysis.
Table 9. Principal components observed after the vegetative characterization of wild grapevines native to the state of Puebla, Mexico.

\begin{tabular}{lcc}
\hline $\begin{array}{l}\text { Principal } \\
\text { component }\end{array}$ & $\begin{array}{c}\text { Observed } \\
\text { variance (\%) }\end{array}$ & $\begin{array}{c}\text { Cumulative } \\
\text { variance (\%) }\end{array}$ \\
\hline 1 & 37.7 & 37.7 \\
2 & 26.9 & 64.6 \\
3 & 11.8 & 76.4 \\
4 & 10.3 & 86.7 \\
5 & 8.2 & 94.9 \\
6 & 5.1 & 100.0 \\
\hline
\end{tabular}

Overlapping the performance of Vitis accessions on the two principal component graphs (Fig. 4), it was observed that the accessions from Tehuacán were always in Sectors II and III (SII and SIII); accessions native to Atlixco were present in the four sectors, except SII; and those native to Teziutlán were observed in the four sectors, but only one accession was in SIII. These results agreed with the previous idea, suggesting that accessions of the Tehuacán region had lower vegetative variability; this fact might be related to the effect of local inhabitant selection; like in that region, specifically in the locality of Chapulco (see Table 3), wild grapevine berries are commercialized and they are rustically trained, that is, they present scanty agronomical management. On the other hand, accessions from Atlixco and Teziutlán showed higher variability; the Atlixco region is formed by three subregions related to warm, semiwarm, and temperate climates; it is possible that the different environments determined, at least in part, the diversity of that region. In Teziutlán, in addition to the presence of at least two main climates, Vitis plants were located in places with low human activities (Franco-Mora et al., 2008), suggesting that this factor might contribute to preserving diversity of wild grapevine. Moreover, the high influence of ML general shape of petiole sinus on principal Component 1 suggests it as an important and easy to observe descriptor for Vitis spp., although the rest of IPGRI suggested descriptors have their own influence and importance.

\section{Conclusions}

Thirty-four accessions native to Puebla were morphologically described after vegetative descriptions based on 32 vegetative characters; only six of them were selected for cluster analysis because their analysis of principal components explained $100 \%$ of the variability with only the first six principal components. At a euclidean distance of 18 , four groups were formed; in Groups 1 and 2, the presence of accessions of the three regions was observed; on the other hand, accessions native to Atlixco and Teziutlán regions were located in four and three of the four formed clusters, suggesting higher variability on Vitis native to those former regions.

HortScience Vol. 43(7) December 2008 


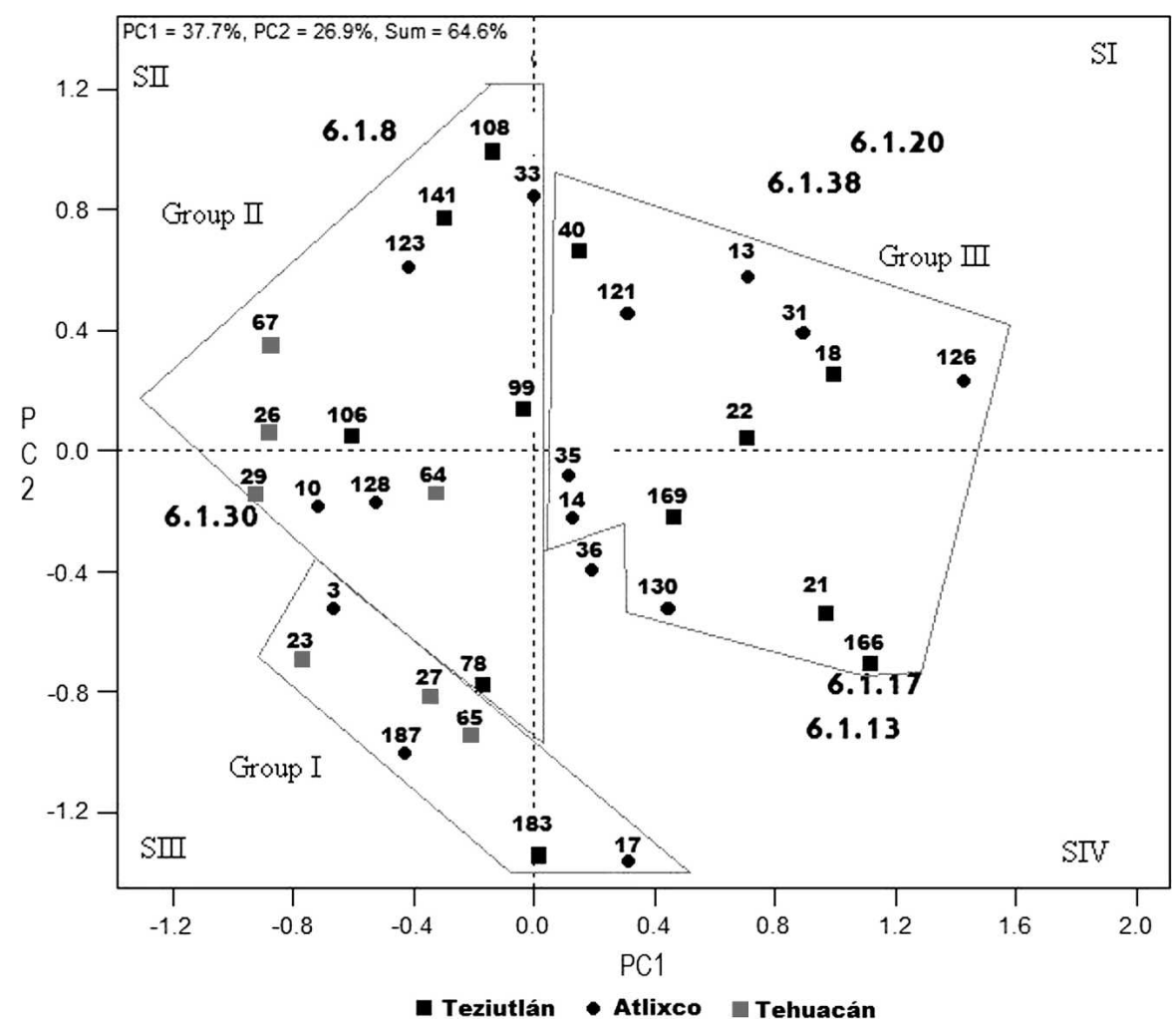

Fig. 4. Principal component analysis using six highly correlated vegetative characters (IPGRI) and their relationship with Vitis native to three states of the Puebla region.

\section{Literature Cited}

Arroyo-García, R., L. Ruíz-García, L. Bolling, R. Ocete, M.A. López, C. Arnold, A. Ergul, G. Söylemezoğlu, H.I. Uzun, F. Cabello, J. Ibáñez, M.K. Aradhya, A. Atanassov, I. Atanassov, S. Balint, J.L. Cenis, L. Constantini, S. Goris-Lavets, M.S. Grando, B.Y. Klein, P.E. McGovernn, D. Merdinoglu, L. Pejic, F. Pelsy, N. Primikirios, V. Risovannaya, K.A. Roubelakis-Angelakis, H. Snoussi, P. Sotiri, S. Tamhankar, P. This, L. Troshin, M. Malpica, F. Lefort, and J.M. Martínez-Zapater. 2006. Multiple origins of cultivated grapevine (Vitis vinifera L. ssp. sativa) based on chloroplast DNA polymorphisms. Mol. Ecol. 15:3707-3714.

Asencio, M.L., E. Valdés, and F. Cabello. 2002. Characterisation of some Spanish white grapevines cultivars by morphology and amino acid analysis. Sci. Hort. 93:289-299.
Boursiquot, J.M. 2000. Development of methods for the conservation and the management of grape genetic resources. Acta Hort. 528:33-38.

Camargo, U.A. 2000. Grape breeding for the subtropical and tropical regions of Brazil. Acta Hort. 528:473-477.

Cruz, C.J.G. 2007. Uvas silvestres (Vitis): Distribución y usos en la región central de Veracruz, p. 225-235. In: Nieto, R.A. (ed.). Frutales nativos, un recurso fitogenético de México. Universidad Autónoma Chapingo, Chapingo.

Franco-Mora, O., A.A. Cortés-Sánchez, A.C. Rodríguez-Landero, J.G. Cruz-Castillo, J.M. Pérez, and J. Madero-Tamargo. 2007. Location of wild grapevine (Vitis spp.) in the state of Puebla, México. HortScience 42:1008 (abstr.).

Franco-Mora, O., J.G. Cruz-Castillo, A.A. CortésSánchez, and A.C. Rodríguez-Landero. 2008. Location and uses of wild grapevine (Vitis spp.) in the state of Puebla, México. Ra Ximhai $4: 151-165$.

Huang, K.S. and M. Lin. 1999. Oligoestilbenes from the roots of Vitis amurensis. J. Asian Nat. Prod. Res. 2:21-28.

IPGRI, UPOV, and OIV. 1997. Descriptors for grapevine (Vitis spp.). International Plant Genetic Institute, Rome, Italy.

Li, Y.-t., C.-s. Yao, J.-y. Bai, M. Lin, and G.-f. Cheng. 2006. Anti-inflammatory effect of amurensin $\mathrm{H}$ on asthma-like reaction induced by allergen in sensitive mice. Acta Pharm. Sin. 27:735-740

Lu, M.C. 2005. Micropropagation of Vitis thunbergii Screb. et Zucc., a medical herb, trough high-frequency shoot tip culture. Sci. Hort. 107:64-69.

Martí, C., J. Cassanova, C. Montaner, and D. Badia. 2006. Ampelometric study of mature leaves from two indigenous Vitis cultivars grown in Somontano de Barbastro. J. Wine Res. 17:185-194.

Martínez, M.A., V. Evangelista, F. Basurto, M Mendoza, and A. Cruz-Rivas. 2007. Flora útil de los cafetales en la Sierra Norte de Puebla, México. Rev. Mex. Biodiv. 78:15-40.

Motosugi, H., Y. Yamamoto, T. Narau, and D. Yamaguchi. 2007. Growth and fruit quality of 'Kyoho' grapevines grafted on autotetraploid rootstocks. J. Jpn. Soc. Hort. Sci. 76:271-278.

Navarro, S., M. León, L. Roca-Pérez, R. Boluda, L. García-Ferriz, P. Pérez-Bermúdez, and I. Gavidia. 2008. Characterisation of Bobal and Crujidera grape cultivars, in comparation with Tempranillo and Cabernet Sauvignon: Evolution of leaf macronutrients and berry composition during grape ripening. Food Chem. 108:182-190.

Ocete, R., M.A. López, A. Gallardo, and C. Arnold. 2008. Comparative analysis of wild and cultivate grapevine (Vitis vinifera) in the Basque region of Spain and France. Agr. Ecos. Env. 123:95-98.

Ocete, R., M.A. López, M. Lara, and R. Del Tío. 1997. The sanitary state of a phytogenetic resource: The Spanish wild grapevine, Vitis vinifera sylvestris Gmelin (Hegi), populations. Plant Gen. Res. Newsletter 110:5-12.

Oshima, Y. and A. Kamijou. 1995. Novel oligostilbenes from Vitis coignetiae. Tetrahedron 51:11979-11986.

Santiago, J.L., S. Boso, P. Gago, V. AlonsoVillaverde, and M.C. Martínez. 2008. A contribution to the maintenance of grapevine diversity: The rescue of Tinta Castañal (Vitis vinifera L.), a variety on the edge of extinction. Sci. Hort. 116:199-204. 